\title{
Silencing Dkk1 expression rescues dexamethasone-induced suppression of primary human osteoblast differentiation
}

\author{
Joseph S Butler ${ }^{1,2^{*}}$, Joseph M Queally ${ }^{1,2}$, Brian M Devitt ${ }^{1,2}$, David W Murray ${ }^{1}$, Peter P Doran ${ }^{1}$, John M O'Byrne ${ }^{2}$
}

\begin{abstract}
Background: The Wnt/ $\beta$-catenin pathway is a major signaling cascade in bone biology, playing a key role in bone development and remodeling. The objectives of this study were firstly, to determine the effects of dexamethasone exposure on Wnt/ $\beta$-catenin signaling at an intracellular and transcriptional level, and secondly, to assess the phenotypic effects of silencing the Wnt antagonist, Dickkopf-1 (Dkk1) in the setting of dexamethasone exposure.

Methods: Primary human osteoblasts were exposed in vitro to $10^{-8} \mathrm{M}$ dexamethasone over a $72 \mathrm{~h}$ time course. The phenotypic marker of osteoblast differentiation was analyzed was alkaline phosphatase activity. Intracellular $\beta$-catenin trafficking was assessed using immunoflourescence staining and TCF/LEF mediated transcription was analyzed using a Wht luciferase reporter assay. Dkk1 expression was silenced using small interfering RNA (siRNA).

Results: Primary human osteoblasts exposed to dexamethasone displayed a significant reductions in alkaline phosphatase activity over a $72 \mathrm{~h}$ time course. Immunoflourescence analaysis of $\beta$-catenin localization demonstrated a significant reduction in intracytosolic and intranuclear $\beta$-catenin in response to dexamethasone exposure. These changes were associated with a reduction of TCF/LEF mediated transcription. Silencing Dkk1 expression in primary human osteoblasts exposed to dexamethasone resulted in an increase in alkaline phosphatase activity when compared to scrambled control.

Conclusions: Wnt/ $\beta$-catenin signaling plays a key role in regulating glucocorticoid-induced osteoporosis in vitro. Silencing Dkk1 expression rescues dexamethasone-induced suppression of primary human osteoblast differentiation. Targeting of the Wnt/ $\beta$-catenin signaling pathway offers an exciting opportunity to develop novel anabolic bone agents to treat osteoporosis and disorders of bone mass.
\end{abstract}

\section{Background}

Osteoporosis is a systemic skeletal disorder characterized by low bone mass and a progressive micro-architectural deterioration of bone tissue, leading to an increase in bone fragility and ultimately susceptibility to fracture [1]. There has been an increasing interest in elucidating the role played by developmental pathways, such as Wnt/ $\beta$-catenin cascade, in bone mass regulation [2].

Wnt proteins are a family of secreted cysteine-rich glycoproteins with functions relating to cell specification, formation of the body plan, cell growth, proliferation, differentiation and apoptosis [3-5]. Wnts are

\footnotetext{
* Correspondence: josephsbutler@hotmail.com

'Clinical Research Centre, UCD School of Medicine \& Medical Science, Mater Misericordiae University Hospital, Dublin, Ireland

Full list of author information is available at the end of the article
}

defined by their sequence homology to Drosophila wingless and the murine int-1 proto-oncogene. Human and mouse genomes have been shown to encode 19 and $18 \mathrm{Wnt}$ genes, respectively [6]. Wnt proteins activate a number of distinct intracellular signal transduction pathways which have been implicated in numerous developmental and disease processes.

The role of canonical Wnt signaling in bone development and remodeling was first identified when the lossof-function mutation of the LDL receptor-related protein (LRP5) was associated with osteoporosis psuedoglioma syndrome, a recessive disorder characterized by osteogenesis imperfecta with low bone mass and a predisposition to fractures as well as ocular defects $[7,8]$. Subsequently, gain-of-function mutations of the LRP5 have been shown to be associated with disorders of

\section{C) Biomed Central}


increased bone mass, such as Van Buchem's disease, osteopetrosis, and endosteal hyperostosis [9-11].

In this study, we focused our attention on the role played by $\mathrm{Wnt} / \beta$-catenin signaling in glucocorticoidinduced osteoporosis. We determined the effects of dexamethasone exposure on $\mathrm{Wnt} / \beta$-catenin signaling in primary human osteoblasts. We also examined the phenotypic effects of attenuating the expression of Dkk1, a Wnt antagonist, in primary human osteoblasts exposed to dexamethasone.

\section{Methods}

\section{Cell Culture}

Primary human osteoblasts from normal human hip samples were (Promocell, Heidelberg, Germany). Cells were cultured in Osteoblast Growth Medium (Promocell, Heidelberg, Germany) containing 10\% FCS and antibiotics $(100 \mathrm{IU} / \mathrm{ml}$ penicillin and $100 \mu \mathrm{g} / \mathrm{ml}$ streptomycin) at $37^{\circ} \mathrm{C}, 5 \% \mathrm{CO}_{2}$. For all experiments primary human osteoblasts used were between $2^{\text {th }}$ and $5^{\text {th }}$ passage. Cells were treated over a $48 \mathrm{~h}$ time course with $10^{-8}$ M Dexamethasone (Dex) (Sigma-Aldrich, Poole, UK). Institutional Review Board approval for this study was obtained from the Mater Misericordiae University Hospital Research Ethics Committee.

\section{Alkaline Phosphatase Activity}

Alkaline phosphatase (ALP) activity was assayed by the measurement of released $p$-nitrophenol from $p$-nitrophenolphosphate (pNPP). Post-treatment cell lysates were collected by Cell Lytic MT (Sigma-Aldrich, Poole, $\mathrm{UK})$ treatment and the extracted protein was frozen at $-80^{\circ} \mathrm{C}$ for at least $2 \mathrm{~h}$ prior to ALP activity assay to disrupt cellular membranes. $10 \mu \mathrm{l}$ of thawed cell lysates were incubated with $200 \mu \mathrm{l} p \mathrm{NPP}$ reagent (SigmaAldrich, Poole, UK) for $30 \mathrm{~min}$ at room temperature. ALP activity was measured at $405 \mathrm{~nm}$ and normalized to total protein extracted, which was measured using a bicinchoninic acid (BCA) protein assay kit (Pierce, Rochford, Illinois). One unit of ALP activity was defined as the amount required for the liberation of $1.0 \mu \mathrm{mol}$ $p$-nitrophenol $/ \mathrm{min} / \mathrm{mg}$ of cellular protein.

\section{Immunoflourescence Staining}

Beta-catenin was visualized by indirect immunocytochemistry using a mouse anti $\beta$-catenin (Santa Cruz Biotechnology, Santa Cruz, CA, USA) as the primary antibody. Primary human osteoblasts were plated on coverslips and treated with Dex-containing media. Cells were fixed in ice-cold methanol and permeabilized for ten minutes. Cells were then blocked with $10 \%$ goat serum for ten minutes at room temperature. Samples were incubated for $1 \mathrm{hr}$ with primary antibody followed by a $30 \mathrm{~min}$ incubation with a goat anti-mouse TRITC- conjugate. Cells were viewed with a Zeiss Axioskop 40 fluorescence microscope using $20 \times$ objectives. Digital images were captured with a ProgRes $\mathrm{C} 10^{\text {plus }}$ research digital camera (Jenoptik Laser Optik Systeme GmbH, Jena, Germany). The digital images were processed using the ProgRes CapturePro 2.1 image analysis softwear package (Jenoptik Laser Optik Systeme GmbH, Jena, Germany).

\section{Generation of Conditioned Media}

Mouse Wnt3a overexpressing cells (L-Wnt3a) and control non-transfected L-cells were obtained from the American Type Culture Collection (ATCC, Manassas, USA) and cultured in DMEM with glutamax, 10\% FBS, $100 \mathrm{IU} / \mathrm{ml}$ penicillin and $100 \mu \mathrm{g} / \mathrm{ml}$ streptomycin. L-Wnt3a culture medium was supplemented with $400 \mu \mathrm{g} / \mathrm{ml}$ geneticin to maintain selective pressure. Conditioned medium from L-Wnt3a and control L-cells was collected according to the manufacturer's instructions. Briefly, cells were passaged 1:10 in $8 \mathrm{ml}$ medium without geneticin and left to grow for 10 days. Medium was collected from each cell line and replaced with $8 \mathrm{ml}$ fresh medium for a further 3 days. This second batch of medium was then collected and the cells discarded. First and second batches were combined, sterile filtered $(0.2 \mu \mathrm{m})$ and stored at $-20^{\circ} \mathrm{C}$ until required.

\section{$\beta$-Catenin/TCF Transcription Reporter Assay}

Primary human osteoblasts plated in 24-well plates at $2 \times 10^{4} / \mathrm{cm}^{2}$ were transiently transfected with the Wntluciferase reporter construct pBAR $(1 \mu$ g total; Dr. RT. Moon, University of Washington, Seattle, WA, USA) and the control reporter pfuBAR $(1 \mu \mathrm{g}$ total; Dr. RT. Moon, University of Washington, Seattle, WA, USA) using GeneJuice (Novagen, Madison, WI, USA). The $\beta$-catenin activated reporter (pBAR) contains $12 \mathrm{TCF}$ binding sites (5'-AGATCAAAGG-3') separated by distinct 5 base linkers. These elements are directly upstream of a minimal thymidine kinase promoter which then drives the expression of firefly luciferase. The control reporter pfuBAR is identical to its sister reporter with the exception of a two base substitution in each TCF binding site. Both reporters contain a separate PGK promoter that constitutively drives the expression of a puromycin resistance gene, and both are in a lentiviral platform. Co-transfection with $0.5 \mu \mathrm{g}$ of the internal control reporter pSL9EF1a(P)RLUC (Dr. RT. Moon, University of Washington, Seattle, WA, USA), driving constitutive expression of Renilla luciferase, was systematically performed to normalize for transfection efficiency. Sixteen hours after transfection, cells were washed and cultured for $48 \mathrm{hr}$ in Dex-containing media with $2 \%$ FCS, in the presence or absence Wnt3aconditioned media. Cells were lysated, and luciferase 
assays were performed with the Dual Luciferase Assay Kit (Promega, Madison, WI, USA) according to manufacturer's instructions. $10 \mu \mathrm{l}$ of cell lysates were first assayed for firefly luciferase and then Renilla luciferase activity. Firefly luciferase activity was normalized to Renilla luciferase activity.

\section{siRNA-mediated Dkk1 Gene Silencing}

Predesigned short interfering RNA (siRNA) targeting human Dkk1 (Hs_DKK1_1) and a control scrambled RNA targeting a sequence not sharing homology with the human genome (AllStars Negative Control) were purchased (Qiagen, Crawley, UK). Primary human osteoblasts were transfected with siRNAs and control scrambled RNA using the RNAiFect transfection reagent (Qiagen, Crawley, UK) as per manufacturer's protocol. Briefly, siRNA or scrambled RNA solutions were prepared 15-25 min before the cell transfection. The ratio of siRNA to the RNAiFect reagent was $1 \mu \mathrm{g}$ siRNA to $3 \mu \mathrm{l}$ transfection reagent. The siRNA-RNAiFect transfection complexes were incubated for $15 \mathrm{~min}$ at room temperature $\left(15-25^{\circ} \mathrm{C}\right)$. Osteoblast growth medium was replaced with fresh medium and the siRNA-RNAiFect suspension was added drop-wise onto the cells. The cells with adherent complexes were incubated for $24 \mathrm{~h}$ at $37^{\circ} \mathrm{C}, 5 \% \mathrm{CO}_{2}$, at which point the medium was changed and experimentation was commenced. Transfection efficiency was determined in three preliminary experiments in which a fluorescent control RNA-RNAiFect complex (Qiagen, Crawley, UK) was transfected into the cells instead of the siRNA-RNAiFect complex. The uptake of the fluorescent RNA as determined by fluorescence microscopy was in the range of $75-85 \%$. The ratio of siRNA to the RNAiFect reagent was determined three preliminary experiments with a ratio of $1 \mu \mathrm{g}$ siRNA:3 $\mu \mathrm{l}$ RNAiFect providing a maximal gene silencing of $75 \%$ knockdown as determined by qRT-PCR.

\section{Quantitative Real Time PCR}

Dkk-1 mRNA regulation in primary human osteoblasts treated with dexamethasone was measured by quantitative Real Time PCR using human Dkk-1 QuantiTect assay (Qiagen, Crawley, UK). The QuantiProbe sequence for Dkk-1 was 5'-CACACCAAAGGACAAGA-3'. The forward primer sequence for Dkk-1 was 5'-GGGAATTACTGCAAAAATGGAATA-3', and the reverse primer sequence was 5'-ATGACCGGAGACAAACAGAAC-3'. Total RNA was extracted by TRI-reagent/chlorophorm method, then assayed in duplicate using a Rotorgene 3.0 Real Time PCR instrument (Corbett Research, Cambridge, UK) and the Real Time PCR amplification kit SYBR Green I (Qiagen, Crawley, UK). Using gene specific primer pairs, Dkk1 gene products were measured by Absolute Quantification and were reported as a function of crossing time $(\mathrm{Ct})$, the cycle number at which PCR amplification becomes linear. mRNA expression was normalized to control and GAPDH expression resulting in Mean Fold Change values or $\Delta \Delta$ Ct. Following cycling, to ensure specificity, melt curve analysis was carried out to verify the amplification of $\mathrm{PCR}$ products starting at $65^{\circ} \mathrm{C}$ and ramping to $95^{\circ} \mathrm{C}$ at $0.1^{\circ} \mathrm{C} / \mathrm{sec}$. One peak in the melt curve indicated no secondary, non-specific products were formed.

\section{Dkk1 ELISA}

Human Dkk1 ELISA kit (R\&D Systems Europe Ltd, Abingdon, UK) was obtained to analyse Dkk1 protein expression on cell supernatant. ELISA was performed in accordance with manufacturer's protocols.

\section{Statistical Analysis}

All experimental data presented were obtained from three independent experiments, each in triplicate. Data were expressed as mean \pm SE. Statistical differences were calculated using Student's $t$-test or ANOVA for multiple comparisons. $p$ values $<0.05$ was considered statistically significant.

\section{Results}

Dexamethasone exposure in vitro reduces alkaline phosphatase activity deposition in primary human osteoblasts

To study the effects of dexamethasone, on markers of osteoblast differentiation, we exposed primary human osteoblasts to $10^{-8} \mathrm{M}$ dexamethasone over a $72 \mathrm{~h}$ time course. The marker of osteoblast differentiation assessed was alkaline phosphatase activity.

Primary human osteoblasts exposed to dexamethasone in vitro displayed a reduction in alkaline phosphatase activity over a $72 \mathrm{~h}$ time course (Figure 1). Significant reductions in alkaline phosphatase activity were seen at $12 \mathrm{~h}$ ( $\mathrm{p}<0.001), 24 \mathrm{~h}$ ( $\mathrm{p}<0.001), 48$ ( $<<0.001), 72 \mathrm{~h}$ ( $\mathrm{p}<0.001$; Student's $t$-test) of dexamethasone exposure when compared to control primary human osteoblasts (Figure 1).

\section{Dexamethasone-induced inhibition of bone turnover in vitro is driven by a Wnt-dependant mechanism}

In order to determine the effects of dexamethasone exposure on $\mathrm{Wnt} / \beta$-catenin signaling in primary human osteoblasts, we firstly examined $\beta$-catenin trafficking using immunoflourescence analysis. Primary human osteoblasts were grown to confluency and exposed to $10^{-8} \mathrm{M}$ dexamethasone over a $48 \mathrm{~h}$ time course.

Control primary human osteoblasts, not exposed to dexamethasone treatment and cultured in osteoblast growth medium alone, demonstrated a strong perinuclear and intranuclear staining of $\beta$-catenin, representing 


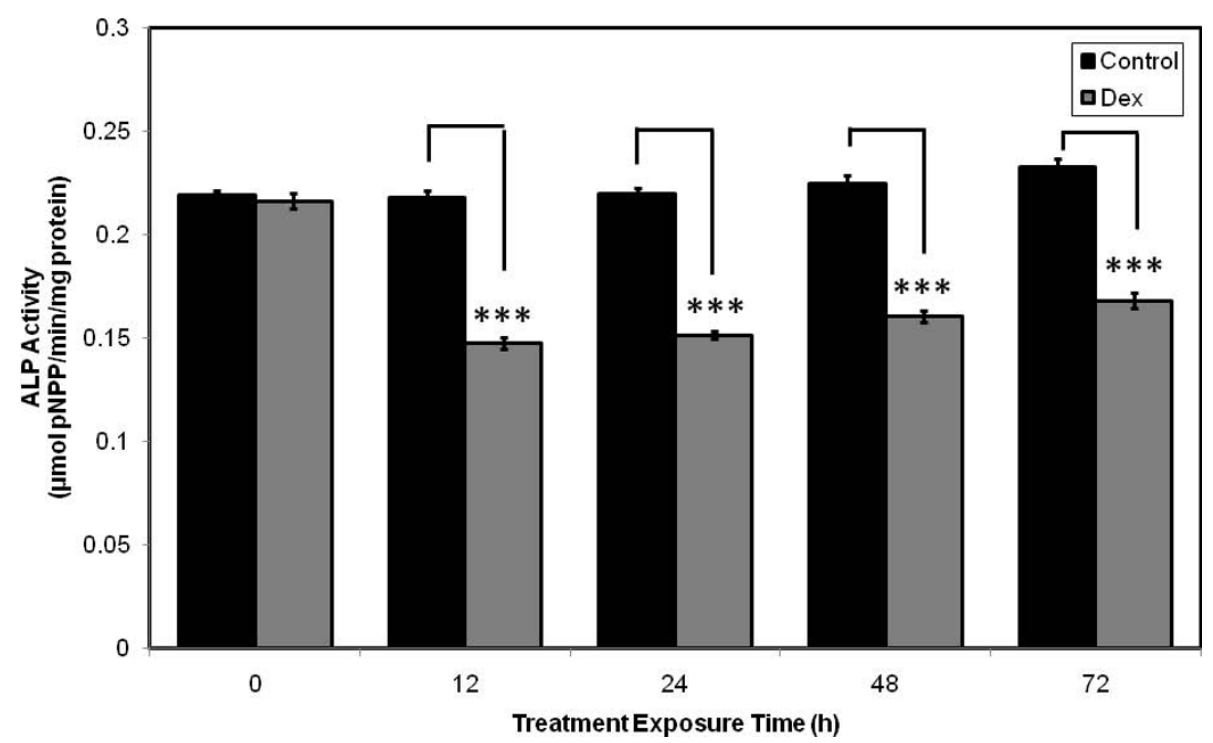

Figure 1 Primary human osteoblasts exposed to dexamethasone in vitro displaying a reduction in alkaline phosphatase activity over a $72 \mathrm{~h}$ time course. Significant reductions in alkaline phosphatase activity and calcium deposition identified at $12 \mathrm{~h}, 24 \mathrm{~h}, 48 \mathrm{~h}$ and $72 \mathrm{~h}$ of dexamethasone exposure when compared to control primary human osteoblasts. ${ }^{* *} p<0.001$ versus control.

activated $W n t / \beta$-catenin signaling (Figure 2a). Primary human osteoblasts exposed to dexamethasone demonstrated a reduction in intracellular staining for $\beta$-catenin at $24 \mathrm{~h}$ (Figure $2 \mathrm{~b}$ ) and this reduction in $\beta$-catenin staining persisted at $48 \mathrm{~h}$ (Figure 2c), representing a significant inhibition of $\mathrm{Wnt} / \beta$-catenin signaling.

Since significant changes in intracellular $\beta$-catenin trafficking were observed, experiments were performed to elucidate the effects of dexamethasone exposure on Wnt/ $\beta$-catenin signaling at a transcriptional level. We transiently transfected primary human osteoblasts with the highly sensitive Wnt-luciferase reporter construct pBAR and the control reporter pfuBAR, and exposed them to $10^{-8} \mathrm{M}$ dexamethasone over a $48 \mathrm{~h}$ time course. Significant reductions in luciferase activity were identified at $24 \mathrm{~h}(\mathrm{p}<0.01)$ and $48 \mathrm{~h}(\mathrm{p}<0.01$; Student's $t$-test $)$ of dexamethasone treatment in the pBAR reporter cells, and the luciferase activity in the pfuBAR reporter cells remained unchanged during treatment (Figure 3).

In order to validate these findings primary human osteoblasts transfected with pBAR were treated with Wnt 3a conditioned media (Wnt agonist) and L-cell conditioned media (control) over a $48 \mathrm{~h}$ time course. Significant reductions in luciferase activity were identified when $10^{-8} \mathrm{M}$ dexamethasone was added to both Wnt 3a conditioned media $(\mathrm{p}<0.001)$ and control L-cell conditioned media ( $\mathrm{p}<0.05$; Student's $t$-test) over the $48 \mathrm{~h}$ time course, representing a reduction in Wnt/ $\beta$-catenin signaling through the inhibition of TCF/LEF mediated transcription (Figure 4).
Silencing of Dkk1 expression rescues dexamethasoneinduced inhibition of osteoblast differentiation, increasing alkaline phosphatase activity and calcium deposition in primary human osteoblasts

In order to explore the phenotypic effects that aberrations in $\mathrm{Wnt} / \beta$-catenin signaling have on primary human osteoblasts exposed to dexamethasone, we silenced the expression of Dickkopf-1 (Dkk1), a powerful Wnt antagonist, using siRNA. Primary human osteoblasts were transfected with siRNA targeting Dkk1 expression or scrambled control RNA and Dkk1 gene expression was assessed using quantitative RT-PCR (Figure 5) and ELISA (Figure 6) to confirm knockdown. Quantitative RT-PCR confirmed a 75\% reduction in Dkk1 gene expression in the siRNA transfected cells relative to untransfected control cells. This represented a significant reduction when compared to both the scrambled control and transfection control cells (ie. cells treated with RNAiFect alone), which demonstrated no change in Dkk1 gene expression. This reduction in Dkk1 expression was confirmed at protein level when the Dkk1 concentration of cell supernatant was analysed using ELISA. An 85\% reduction in Dkk1 concentration was seen in the cell supernatant of siRNA transfected cells relative to untransfected control cells. This also represented a significant reduction when compared to both scrambled control and transfection control cells.

In order to confirm that knockdown of Dkk1 was inhibiting $\mathrm{Wnt} / \beta$-catenin signaling in primary human osteoblasts, we firstly examined $\beta$-catenin trafficking 


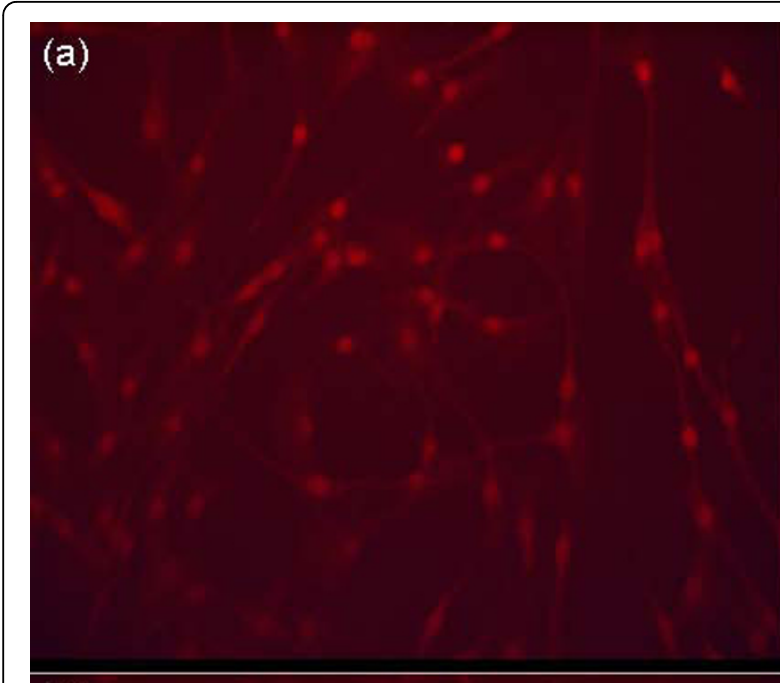

(b)

(c)

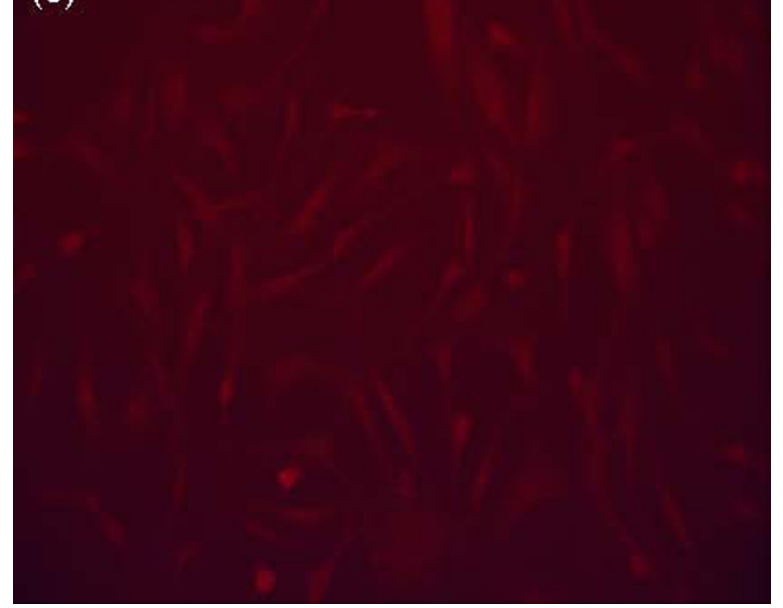

Figure 2 Immunoflourescence microscopy demonstrating $\beta$ catenin expression in primary human osteoblasts exposed to $10^{-8} \mathrm{M}$ dexamethasone over a $48 \mathrm{~h}$ time course. $\beta$-catenin stained with anti- $\beta$-catenin antibody demonstrating its perinuclear and intranuclear localization in control cells (a) and a significant reductions in intracellular localization at $24 \mathrm{~h} \mathrm{(b)} \mathrm{and} 48 \mathrm{~h}$ (c) after treatment. using immunoflourescence analysis. Primary human osteoblasts were grown to confluency and transfected with siRNA targeting Dkk1 expression or scrambled control RNA. siRNA transfected primary human osteoblasts (Figure 7a) demonstrated a strong perinuclear and intranuclear staining of $\beta$-catenin, in comparison to scrambled control primary human osteoblasts (Figure $7 \mathrm{~b}$ ). This represents activation of $\mathrm{Wnt} / \beta$ catenin signaling in response to silencing Dkk1 expression.

These changes in intracellular $\beta$-catenin trafficking were accompanied by changes in Wnt/ $\beta$-catenin signaling at a transcriptional level. Primary human osteoblasts transfected with Wnt-luciferase reporter construct pBAR and the control reporter pfuBAR, were subsequently treated with siRNA targeting Dkk1 expression or scrambled control RNA. A significant increase in luciferase activity was observed in the siRNA transfected cells when compared to scrambled control cells ( $\mathrm{p}<0.001$; Student's $t$-test) in the pBAR reporter cells, whilst the luciferase activity in the pfuBAR reporter cells remained unchanged during treatment (Figure 8).

Primary human osteoblasts transfected with siRNA targeting Dkk1 expression or scrambled control RNA were subsequently exposed to $10^{-8} \mathrm{M}$ dexamethasone over a $72 \mathrm{~h}$ time course. Bone turnover was assessed by analyzing alkaline phosphatase activity. Control primary human osteoblasts exposed to dexamethasone over the $72 \mathrm{~h}$ time course displayed reductions in alkaline phosphatase activity at $12 \mathrm{~h}, 24 \mathrm{~h}, 48 \mathrm{~h}$ and $72 \mathrm{~h}$. However, when primary human osteoblasts were transfected with siRNA attenuating Dkk1 expression, there was an increase in alkaline phosphatase activity at each individual time point when compared to scrambled control. Significant increases relative to scrambled control were identified at $12 \mathrm{~h}(\mathrm{p}<0.05), 24 \mathrm{~h}(\mathrm{p}<0.05), 48 \mathrm{~h}$ $(\mathrm{p}<0.01)$ and $72 \mathrm{~h}(\mathrm{p}<0.01$; Student's $t$-test $)$ of dexamethasone exposure (Figure 9).

\section{Discussion}

Osteoporosis is a skeletal disorder characterized by low bone mass and progressive micro-architectural deterioration of bone tissue with a consequent increase in bone fragility and propensity to fracture. Reduced bone mass is a result of an imbalance between the tightly regulated processes of bone formation and bone resorption, controlled by osteoblasts and osteoclasts respectively. There have been many cell signaling cascades linked to bone mass regulation. One pathway seen as critical for bone mass accrual, bone remodeling and even fracture repair is the $\mathrm{Wnt} / \beta$-catenin pathway.

The Wnt/ $\beta$-catenin pathway plays an important role in the development and maintenance of many tissues and organs, with disturbances in Wnt signaling 


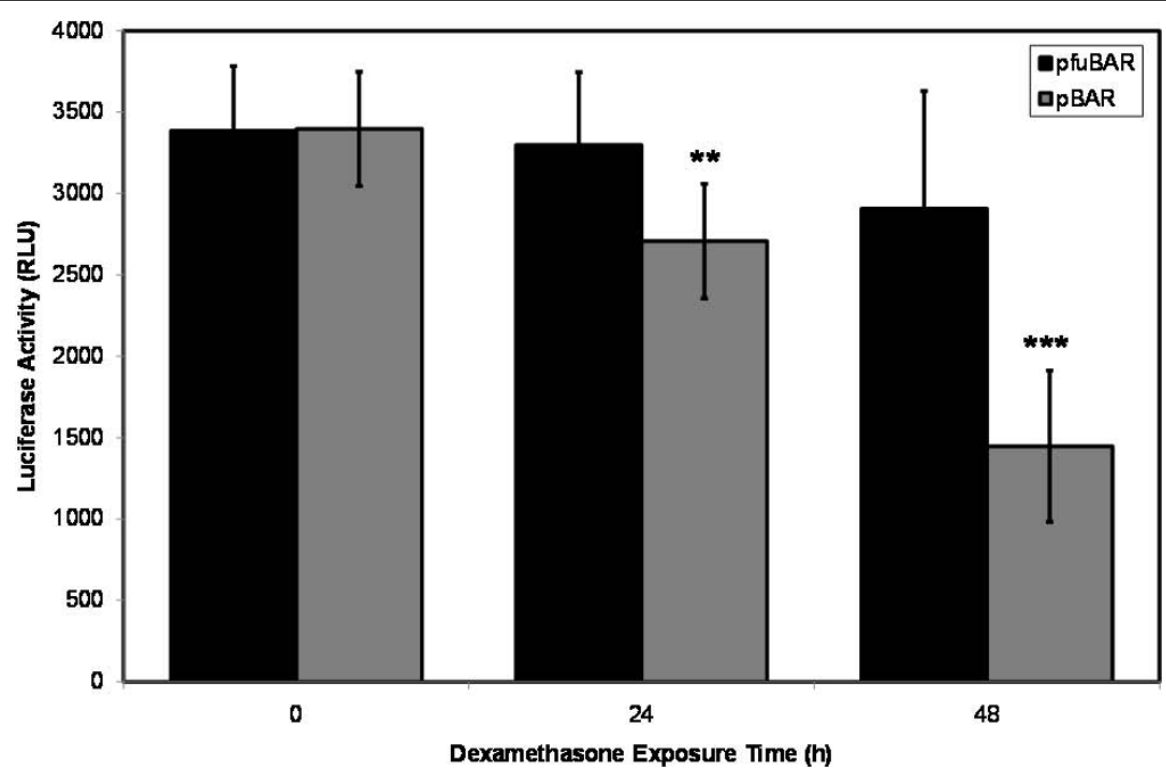

Figure $3 \mathrm{~A}$ reduction in $\beta$-catenin expression during dexamethasone treatment results in a reduction in Wnt/ $\beta$-catenin signaling through TCF/LEF mediated transcription. Primary human osteoblasts were transiently transfected with pBAR (wild type promoter) and pfuBAR (mutant promoter), and exposed them to $10^{-8} \mathrm{M}$ dexamethasone over a $48 \mathrm{~h}$ time course. Significant reductions in luciferase activity were identified at $24 \mathrm{~h}$ and $48 \mathrm{~h}$ after treatment in the pBAR cells, whilst luciferase activity in the pfuBAR cells remained unchanged. ${ }^{* *} \mathrm{p}<0.01$, ${ }^{* * *} p<0.001$ versus pfuBAR.

implicated in multiple disease processes [5,12]. Recent evidence has implicated the Wnt $\beta$-catenin pathway as a major signaling cascades in bone biology [13-17]. Human genetic studies have revealed a critical role of the $\mathrm{Wnt} / \beta$-catenin pathway in bone mass acquisition and maintenance [18]. Loss of function of the Wnt coreceptor, LRP5, have been shown to lead to disorders of decreased bone mass, such as Osteoporosis Pseudoglioma Syndrome (OPS) [7]. Whereas, gain of function mutations of LRP5 have been shown to lead to disorders

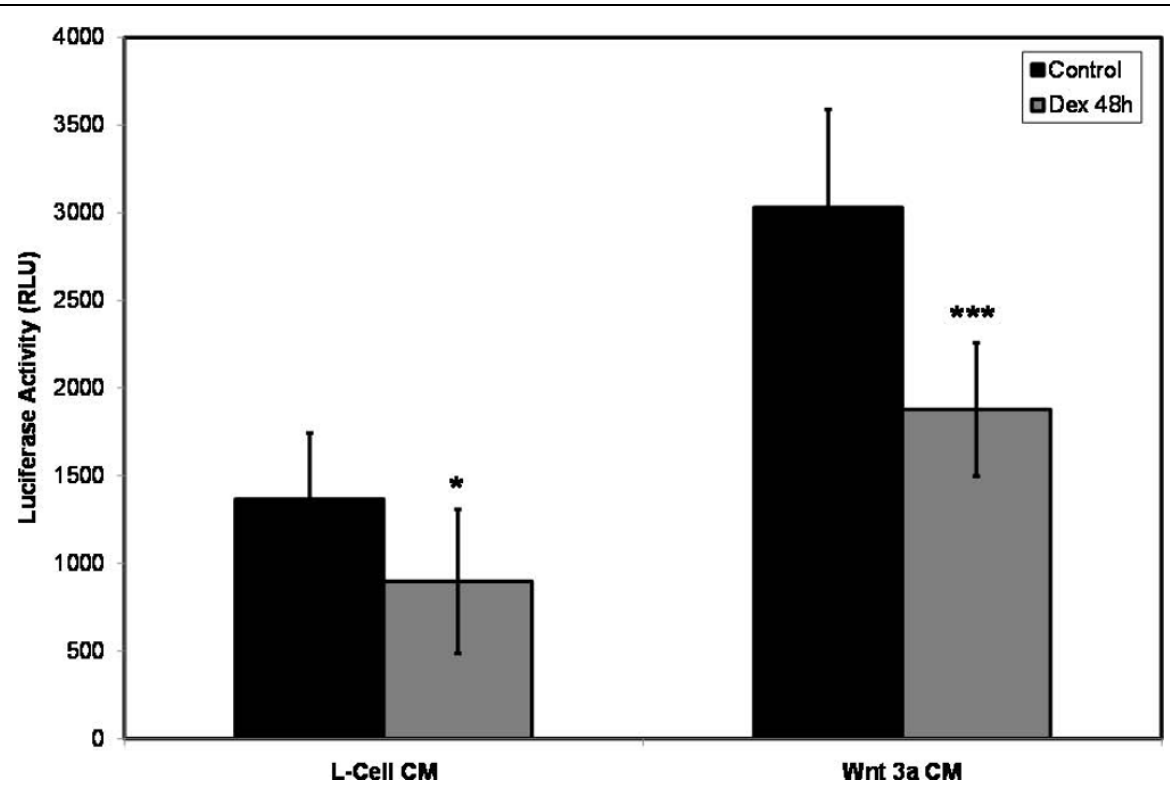

Figure 4 In order to validate these findings, cells transfected with pBAR were treated with Wnt 3a conditioned media (Wnt agonist) and L-cell conditioned media (control). Significant reductions in luciferase activity were identified when $10^{-8} \mathrm{M}$ dexamethasone was added to both conditioned media over a 48 hr time course. ${ }^{*} p<0.05,{ }^{* *} p<0.001$ versus control. 


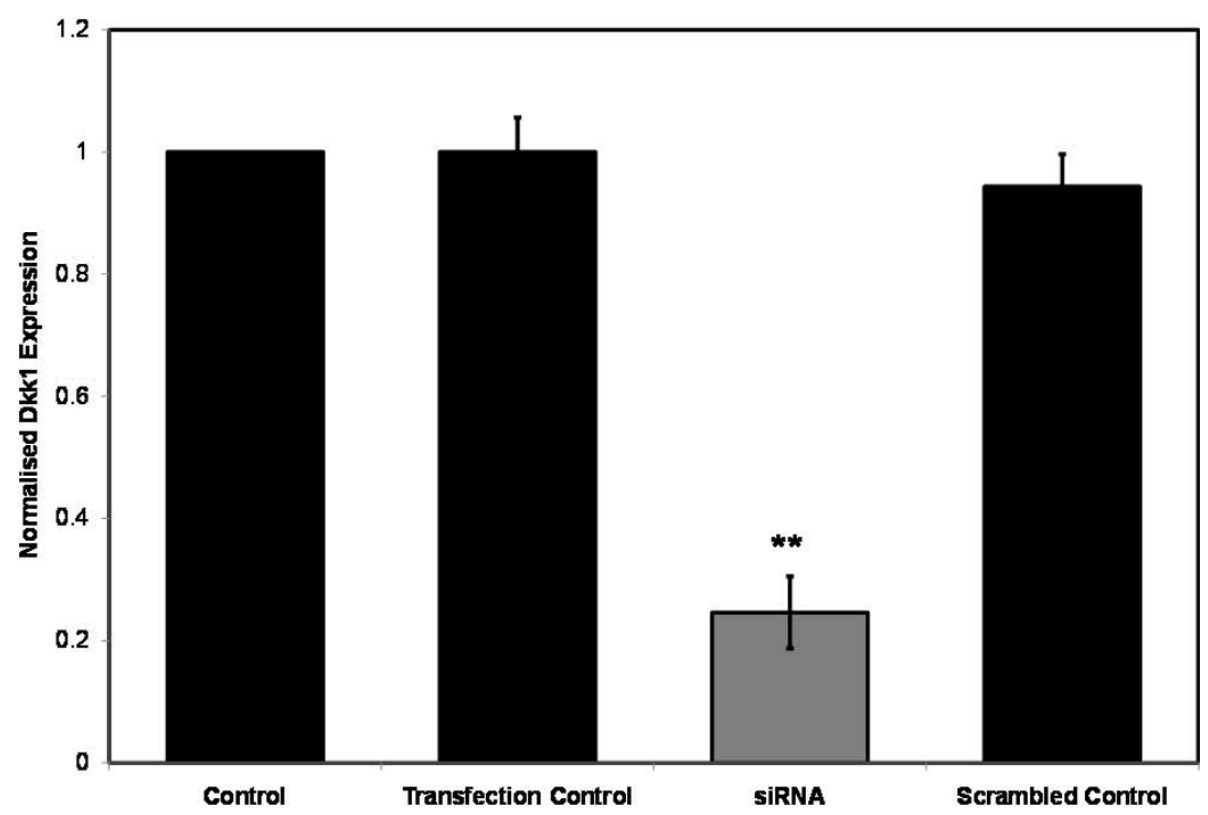

Figure 5 Primary human osteoblasts transfected with siRNA targeting Dkk1 expression or scrambled control RNA. Dkk1 gene expression assessed using quantitative RT-PCR to confirm knockdown. ${ }^{* *} p<0.01$, ${ }^{* * *} p<0.001$ versus transfection control and scrambled control.

of increased bone mass such as sclerostosis [19], Van Buchem's disease [20], osteopetrosis [9] and endosteal hyperostosis [10].

The Dkk family of extracellular proteins consists of four members (Dkk1, Dkk2, Dkk3 and Dkk4). Dkk1 and Dkk2 are the best characterized members of this family. Dkk1 has been shown to inhibit canonical
Wnt/ $\beta$-catenin signaling pathway in several different organisms and cell types [21-25]. The involvement of Dkk2 in regulating bone development was recently demonstrated when it was shown that knockout mice lacking Dkk2 developed osteopenia [26]. Initially increased Dkk1 expression was found to be associated with the lytic bone lesions in patients with multiple

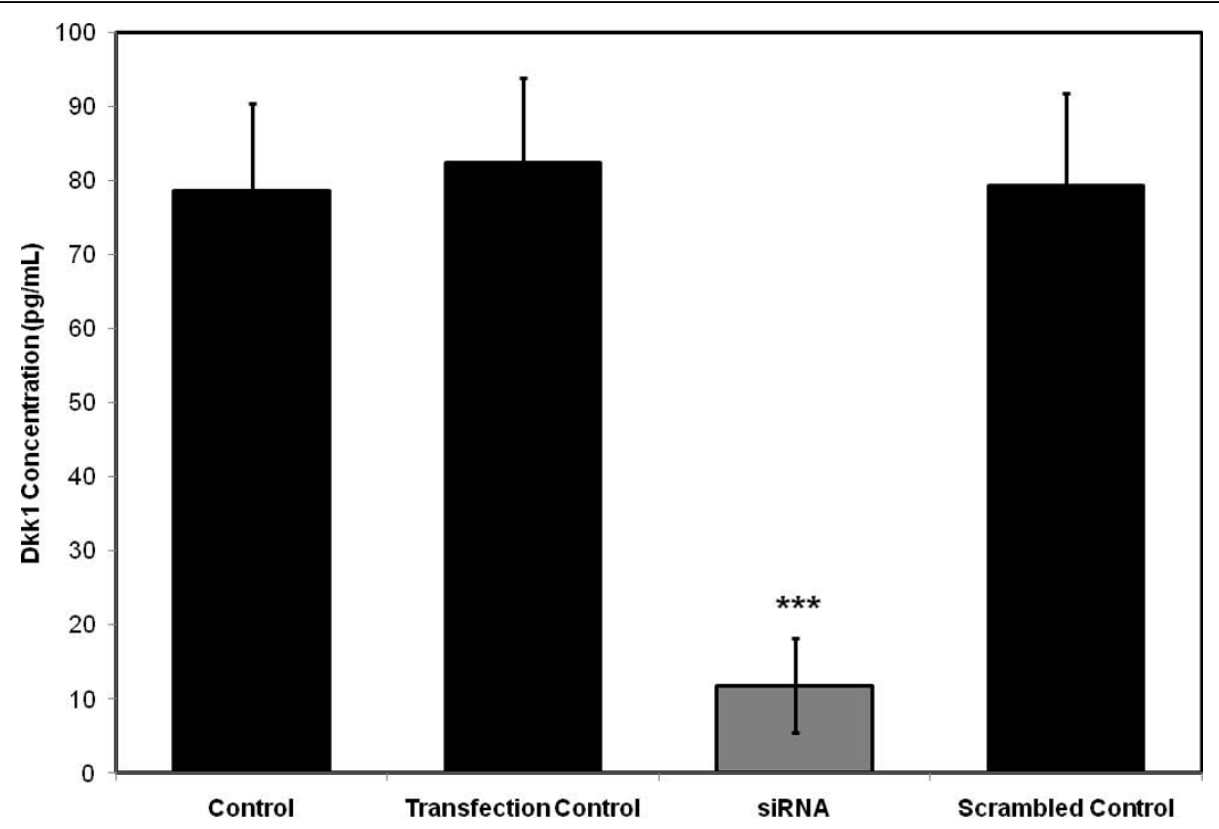

Figure 6 Primary human osteoblasts transfected with siRNA targeting Dkk1 expression or scrambled control RNA. Dkk1 protein expression assessed using ELISA to confirm knockdown. ${ }^{* *} p<0.01,{ }^{* *} p<0.001$ versus transfection control and scrambled control. 


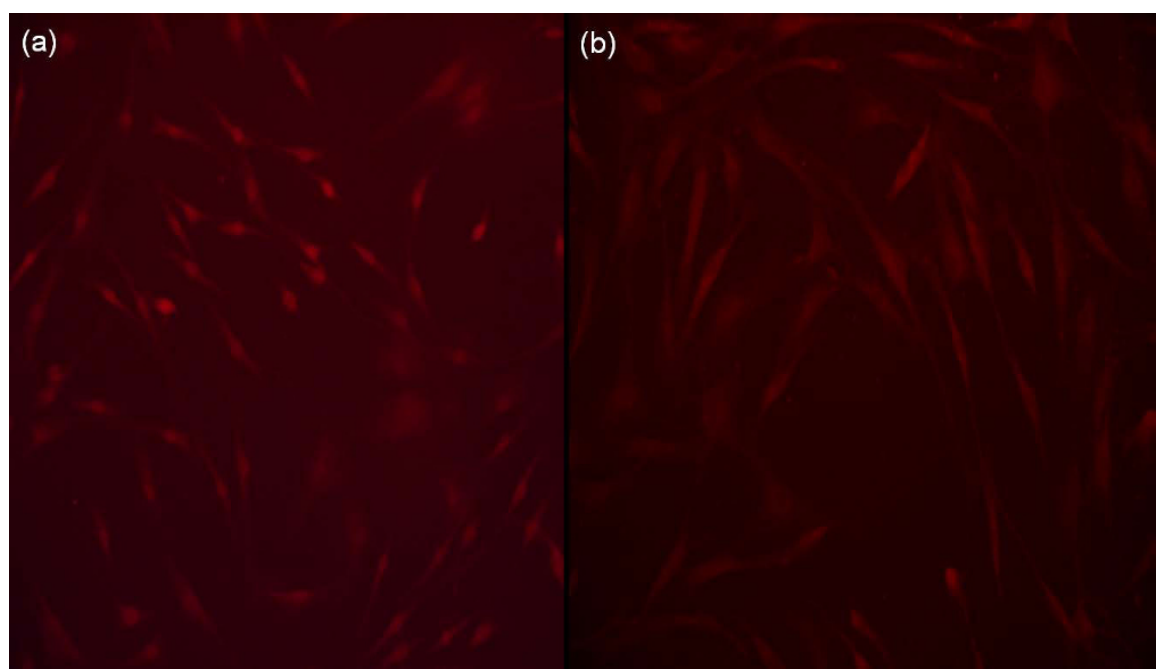

Figure 7 Immunoflourescence microscopy demonstrating $\beta$-catenin expression in primary human osteoblasts transfected with scrambled control RNA (a) or siRNA targeting Dkk1 expression (b). siRNA transfected primary human osteoblasts demonstrated a strong perinuclear and intranuclear staining of $\beta$-catenin, in comparison to scrambled control primary human osteoblasts. This represents activation of Wnt/ $\beta$-catenin signaling in response to silencing Dkk1 expression.

myeloma, suggesting that Dkk1 might inhibit osteoblast differentiation or function [27]. This has been subsequently been reinforced by data showing Dkk1 to be a powerful negative regulator of osteoblast function in vitro and in vivo and that a decrease in its expression is sufficient to induce a strong anabolic response in the skeleton [28-30].
Our data emphasizes the key role of Wnt/ $\beta$-catenin signaling in regulating bone development and remodeling, further strengthening its crucial role in glucocorticoid-induced osteoporosis [31-33]. Primary human osteoblasts exposed to dexamethasone in vitro display a reduction in alkaline phosphatase activity over a $72 \mathrm{~h}$ time course when compared to control osteoblasts.

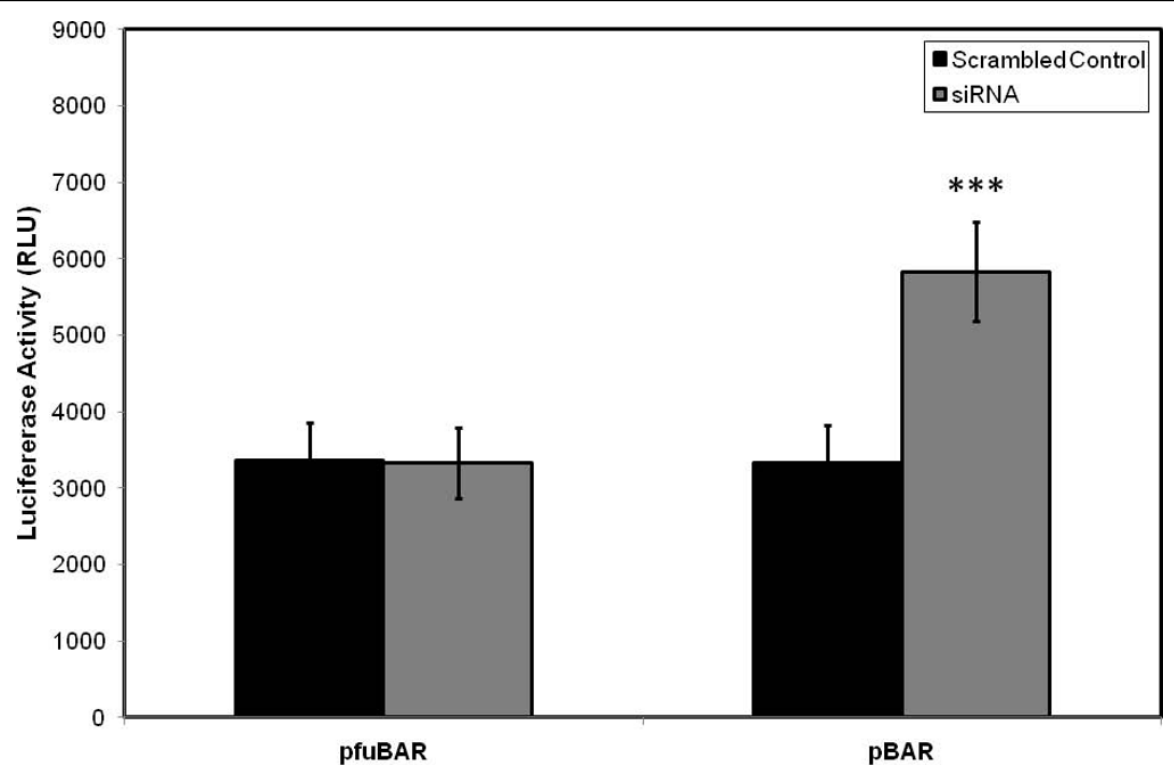

Figure 8 This increase in $\beta$-catenin expression by silencing Dkk1 expression results in an increase in Wnt/ $\beta$-catenin signaling through TCF/LEF mediated transcription. Primary human osteoblasts were transiently transfected with pBAR (wild type promoter) and pfuBAR (mutant promoter), and subsequently treated with siRNA targeting Dkk1 expression or scrambled control RNA. A significant increase in luciferase activity was observed in the siRNA transfected cells when compared to scrambled control cells in the pBAR reporter cells, whilst luciferase activity in the pfuBAR cells remained unchanged (c). ${ }^{* *} p<0.001$ versus scrambled control. 


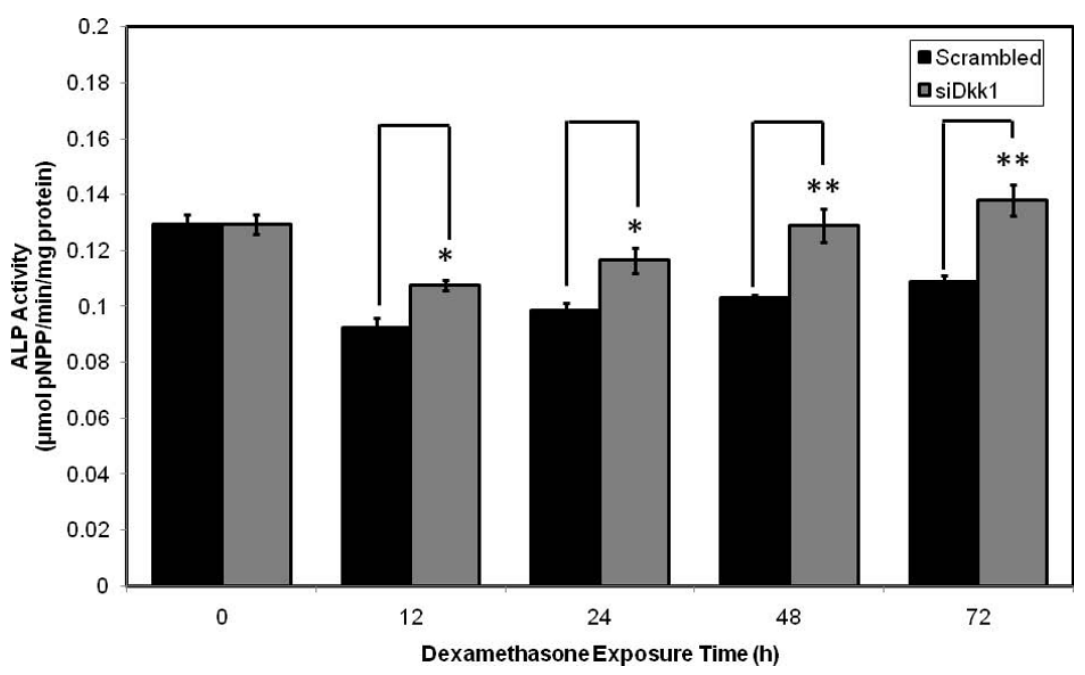

Figure 9 Primary human osteoblasts transfected with siRNA and scrambled control exposed to dexamethasone in vitro compared with respect to alkaline phosphatase activity over a $\mathbf{7 2} \mathbf{~ h}$ time course. Significant increases in alkaline phosphatase activity relative to scrambled control identified at $12 \mathrm{~h}, 24 \mathrm{~h}, 48 \mathrm{~h}$ and $72 \mathrm{~h}$ of dexamethasone exposure. ${ }^{*} p<0.05,{ }^{* *} p<0.01$ versus scrambled control.

These phenotypic changes are driven by a Wnt/ $\beta$-catenin-dependent mechanism as clearly demonstrated by both alterations in $\beta$-catenin trafficking and changes in TCF/LEF-mediated transcription.

Dkk1 is a powerful antagonist of canonical Wnt/ $\beta$-catenin signaling. Silencing Dkk1 expression rescues dexamethasone-induced suppression of primary human osteoblast function. Increased alkaline phosphatase activity was displayed by primary human osteoblasts treated with siRNA targeting Dkk1 expression when compared to scrambled control cells over a $72 \mathrm{~h}$ time course of dexamethasone exposure. The pharmacological targeting of the $\mathrm{Wnt} / \beta$-catenin signaling pathway offers an exciting opportunity for the development of novel anabolic bone agents to treat osteoporosis and disorders of bone mass.

\section{Conclusion}

Wnt $/ \beta$-catenin signaling plays a key role in regulating glucocorticoid-induced osteoporosis in vitro. Silencing Dkk1 expression rescues dexamethasone-induced suppression of primary human osteoblast differentiation. Targeting of the Wnt/ $\beta$-catenin signaling pathway offers an exciting opportunity to develop novel anabolic bone agents to treat osteoporosis and disorders of bone mass.

\section{Acknowledgements}

The authors are supported by grants from the European Union, Cappagh Hospital Trust, Mater College and the Irish Programme for Research in Third Level Institutions

\section{Author details}

${ }^{1}$ Clinical Research Centre, UCD School of Medicine \& Medical Science, Mater Misericordiae University Hospital, Dublin, Ireland. ${ }^{2}$ Department of Trauma \&
Orthopaedic Surgery, Royal College of Surgeons in Ireland, Cappagh National Orthopaedic Hospital, Dublin, Ireland.

\section{Authors' contributions}

JSB performed the majority of the research work. JMQ, BMD and DWM participated in study design, data interpretation and drafted the manuscript. PPD and JMO'B provided direction and oversight regarding all aspects of study design and interpretation of results. All authors have read and approved the final manuscript.

\section{Competing interests}

The authors declare that they have no competing interests.

Received: 22 March 2010 Accepted: 15 September 2010 Published: 15 September 2010

\section{References}

1. NIH Consensus Development Panel on Osteoporosis Prevention Diagnosis Therapy: Osteoporosis prevention, diagnosis, and therapy. JAMA 2001, 285(6):785-95.

2. Hurson CJ, Butler JS, Keating DT, Murray DW, Sadlier DM, O'Byrne JM, Doran PP: Gene expression analysis in human osteoblasts exposed to dexamethasone identifies altered developmental pathways as putative drivers of osteoporosis. BMC Musculoskelet Disord 2007, 8:12.

3. Moon RT, Bowerman B, Boutros M, Perrimon N: The promise and perils of Wnt signaling through beta-catenin. Science 2002, 296:1644-6.

4. Pandur P, Maurus D, Kuhl M: Increasingly complex: new players enter the Wnt signaling network. Bioessays 2002, 24(10):881-4.

5. Logan $C Y$, Nusse R: The Wnt signaling pathway in development and disease. Annu Rev Cell Dev Biol 2004, 20:781-810.

6. Miller JR: The Wnts. Genome Biol 2002, 3(1):REVIEWS3001, Epub 2001 Dec 28.

7. Gong $Y Q$, Slee RB, Fukai N, Rawadi G, Roman-Roman S, Reginato AM, et al: LDL receptor-related protein 5 (LRP5) affects bone accrual and eye development. Cell 2001, 107:513-23.

8. Gong YQ, Vikkula M, Boon L, Liu J, Beighton P, Ramesar R, et al: Osteoporosis-pseudoglioma syndrome, a disorder affecting skeletal strength and vision, is assigned to chromosome region 11q12-13. Am J Hum Genet 1996, 59:146-51.

9. Boyden LM, Mao JH, Belsky J, Mitzner L, Farhi A, Mitnick MA, et al: High bone density due to a mutation in LDL-receptor-related protein $5 . \mathrm{N}$ Engl J Med 2002, 346:1513-21. 
10. Little RD, Carulli JP, Del Mastro RG, Dupuis J, Osborne M, Folz C, et al: A mutation in the LDL receptor-related protein 5 gene results in the autosomal dominant high-bone-mass trait. Am J Hum Genet 2002, 70:11-9.

11. Van Wesenbeeck L, Cleiren E, Gram J, Beals RK, Benichou O, Scopelliti D, et al: Six novel missense mutations in the LDL receptor-related protein 5 (LRP5) gene in different conditions with an increased bone density. Am J Hum Genet 2003, 72:763-71.

12. Moon RT, Kohn AD, De Ferrari GV, Kaykas A: WNT and beta-catenin signalling: diseases and therapies. Nat Rev Genet 2004, 5(9):691-701.

13. Krishnan V, Bryant HU, Macdougald OA: Regulation of bone mass by Wht signaling. J Clin Invest 2006, 116(5):1202-9.

14. Baron R, Rawadi G, Roman-Roman S: Wnt signaling: a key regulator of bone mass. Curr Top Dev Biol 2006, 76:103-27.

15. Westendorf JJ, Kahler RA, Schroeder TM: Wnt signaling in osteoblasts and bone diseases. Gene 2004, 341:19-39.

16. Hoeppner LH, Secreto FJ, Westendorf JJ: Wnt signaling as a therapeutic target for bone diseases. Expert Opin Ther Targets 2009, 13(4):485-96.

17. Rawadi $G$ : Wnt signaling and potential applications in bone diseases. Curr Drug Targets 2008, 9(7):581-90.

18. Johnson ML, Harnish K, Nusse R, Van Hul W: LRP5 and Wnt signaling: a union made for bone. J Bone Miner Res 2004, 19(11):1749-57, Epub 2004 Aug 23.

19. Balemans W, Ebeling M, Patel N, Van Hul E, Olson P, Dioszegi M, et al: Increased bone density in sclerosteosis is due to the deficiency of a novel secreted protein (SOST). Hum Mol Genet 2001, 10(5):537-43.

20. Staehling-Hampton K, Proll S, Paeper BW, Zhao L, Charmley P, et al: A 52$\mathrm{kb}$ deletion in the SOST-MEOX1 intergenic region on 17q12-q21 is associated with van Buchem disease in the Dutch population. Am J Genet 2002, 110(2):144-52.

21. Bafico A, Liu GZ, Yaniv A, Gazit A, Aaronson SA: Novel mechanism of Wnt signalling inhibition mediated by Dickkopf-1 interaction with LRP6/ Arrow. Nat Cell Biol 2001, 3:683-6.

22. Davidson G, Mao BY, Barrantes ID, Niehrs C: Kremen proteins interact with Dickkopf1 to regulate anteroposterior CNS patterning. Development 2002, 129:5587-96.

23. Gregory CA, Singh H, Perry AS, Prockop DJ: The Wnt signaling inhibitor dickkopf- 1 is required for reentry into the cell cycle of human adult stem cells from bone marrow. J Biol Chem 2003, 278:28067-78.

24. Chu EY, Hens J, Andl T, Kairo A, Yamaguchi TP, Brisken C, et al: Canonical WNT signaling promotes mammary placode development and is essential for initiation of mammary gland morphogenesis. Development 2004, 131:4819-29.

25. Kuhnert F, Davis CR, Wang HT, Chu P, Lee M, Yuan J, et al: Essential requirement for Wnt signaling in proliferation of adult small intestine and colon revealed by adenoviral expression of Dickkopf-1. Proc Natl Acad Sci USA 2004, 101:266-71.

26. Li XF, Liu P, Liu WZ, Maye P, Zhang JH, Zhang YH, et al: Dkk2 has a role in terminal osteoblast differentiation and mineralized matrix formation. Nat Genet 2005, 37:945-52.

27. Tian E, Zhan FH, Walker R, Rasmussen E, Ma YP, Barlogie B, et al: The role of the Wnt-signaling antagonist DKK1 in the development of osteolytic lesions in multiple myeloma. N Engl I Med 2003, 349:2483-94.

28. Li J, Sarosi I, Cattley RC, Pretorius J, Asuncion F, Grisanti M, et al: Dkk1mediated inhibition of Wnt signaling in bone results in osteopenia. Bone 2006, 39(4):754-66, Epub 2006 May 26.

29. Morvan F, Boulukos K, Clément-Lacroix P, Roman Roman S, et al: Deletion of a single allele of the Dkk1 gene leads to an increase in bone formation and bone mass. J Bone Miner Res 2006, 21(6):934-45.

30. MacDonald BT, Joiner DM, Oyserman SM, Sharma P, Goldstein SA, et al: Bone mass is inversely proportional to Dkk1 levels in mice. Bone 2007, 41(3):331-9, Epub 2007 Jun 5.

31. Wang FS, Ko JY, Yeh DW, Ke HC, Wu HL: Modulation of Dickkopf-1 attenuates glucocorticoid induction of osteoblast apoptosis, adipocytic differentiation, and bone mass loss. Endocrinology 2008, 149(4):1793-801, Epub 2008 Jan 3.

32. Ohnaka K, Taniguchi H, Kawate H, Nawata H, Takayanagi R: Glucocorticoid enhances the expression of dickkopf-1 in human osteoblasts: novel mechanism of glucocorticoid-induced osteoporosis. Biochem Biophys Res Commun 2004, 318(1):259-64.
33. Ohnaka K, Tanabe M, Kawate H, Nawata H, Takayanagi R: Glucocorticoid suppresses the canonical Wnt signal in cultured human osteoblasts. Biochem Biophys Res Commun 2005, 329(1):177-81.

\section{Pre-publication history}

The pre-publication history for this paper can be accessed here: http://www.biomedcentral.com/1471-2474/11/210/prepub

\section{doi:10.1186/1471-2474-11-210}

Cite this article as: Butler et al:: Silencing Dkk1 expression rescues dexamethasone-induced suppression of primary human osteoblast differentiation. BMC Musculoskeletal Disorders 2010 11:210.

\section{Submit your next manuscript to BioMed Central and take full advantage of:}

- Convenient online submission

- Thorough peer review

- No space constraints or color figure charges

- Immediate publication on acceptance

- Inclusion in PubMed, CAS, Scopus and Google Scholar

- Research which is freely available for redistribution

Submit your manuscript at www.biomedcentral.com/submit
Ciomed Central 